\title{
GANHOS OBTIDOS COM A MUDANÇA DE FORNECEDOR DE PRODUTOS QUÍMICOS NAS TORRES DE RESFRIAMENTO DO SETOR DE UTILIDADES NA CSN*
}

Sueli Aguiar Barros ${ }^{1}$ Jhon Alan de Souza ${ }^{2}$

\section{Resumo}

A água utilizada para refrigerar grandes equipamentos de produção, tais como Alto fornos, Fornos do Laminador de Tiras a Quente, Trocadores de Calor das Laminações de Tiras a Frio é originada de diversas torres de resfriamento da Usina, denominadas CBR's (Casas de Bomba de Refrigeração). A água refrigerada necessita de tratamento químico para proteger os equipamentos de corrosão, deposição e crescimento microbiológico. Este tratamento químico usualmente na CSN é obtido por uma empresa contratada fornecedora de produtos químicos e serviços nestes sistemas. Dentre os serviços destacam-se as análises físico químicas, monitoramento automático das dosagens, avaliação diária dos tratamentos, etc. Recentemente, em Agosto de 2014 houve o início do novo contrato deste tratamento nas nossas CBR's, mudando-se o fornecedor, os produtos e a equipe de atuação nestes sistemas. Este trabalho visa descrever como foi realizada esta mudança, as dificuldades enfrentadas inicialmente e os ganhos obtidos com esta alteração do tratamento. Destacamos os ganhos no monitoramento em certos sistemas que anteriormente não era realizado, como nos Staves do Alto Forno 3 e os ganhos financeiros em relação ao tratamento.

Palavras-chave: Ganhos; Mudança; CBR's.

\section{GAINS WITH THE CHANGE OF SUPPLIER OF CHEMICAL PRODUCTS IN THE COOLING TOWERS OF THE UTILITIES SECTOR IN CSN.}

\section{Abstract}

The water used to cool large production equipments, such as furnaces, furnaces of the hot Strip Mill, heat exchangers, is originated from several cooling towers, called CBR' $s$ (Cooling pump houses). The chilled water requires chemical processing to protect the equipment from corrosion, deposition and microbiological growth. This chemical treatment usually on CSN is obtained by a company contracted as the supplier of chemical products and services in these systems. Among the services, includes the physical and chemical analyses, automatic monitoring of doses, daily evaluation of the treatments, etc. Recently, in August 2014 there was the start of the new contract of this treatment on our CBR' $\mathrm{s}$, changing the supplier, products and expertise in these systems. This work aims to describe how this change was performed, the difficulties faced and the gains made with this change of treatment. We show the gains in certain monitoring systems that previously was not carried out, as in the Staves of Blast furnace 3, and the financial gain in relation to the previous treatment.

Keywords: Earnings; Change; CBR's.

1 Engenheira Química Engenheira Especialista, Gerência de Utilidades, GGCE/GDU, Companhia Siderúrgica Nacional, Volta Redonda, Rio de Janeiro, Brasil.

2 Técnico Mecânico, Líder de Efluentes, Gerência de Utilidades Companhia Siderúrgica Nacional, Volta Redonda, Rio de Janeiro, Brasil. 


\section{INTRODUÇÃO}

O uso de torres de resfriamento representa a maior utilização de água de resfriamento e de reuso de água em aplicações na Usina Presidente Vargas (UPV), na Companhia Siderúrgica Nacional (CSN).

As torres de resfriamento têm a finalidade de remover calor dos processos industriais, usando água como fluido de resfriamento. O seu funcionamento consiste em recircular continuamente a água destes processos, resfriando e protegendo estes sistemas através de tratamento químico. A água que sai dos equipamentos de processo é alimentada e distribuída no topo da torre de resfriamento, constituída de um enchimento interno para melhor distribuição da água. Ar ambiente é insuflado através do enchimento, em contracorrente ou corrente cruzada com a água que desce. Por meio desse contato líquido gás, parte da água evapora e ocorre o seu resfriamento. O princípio de funcionamento da torre está ilustrado na Figura 1.

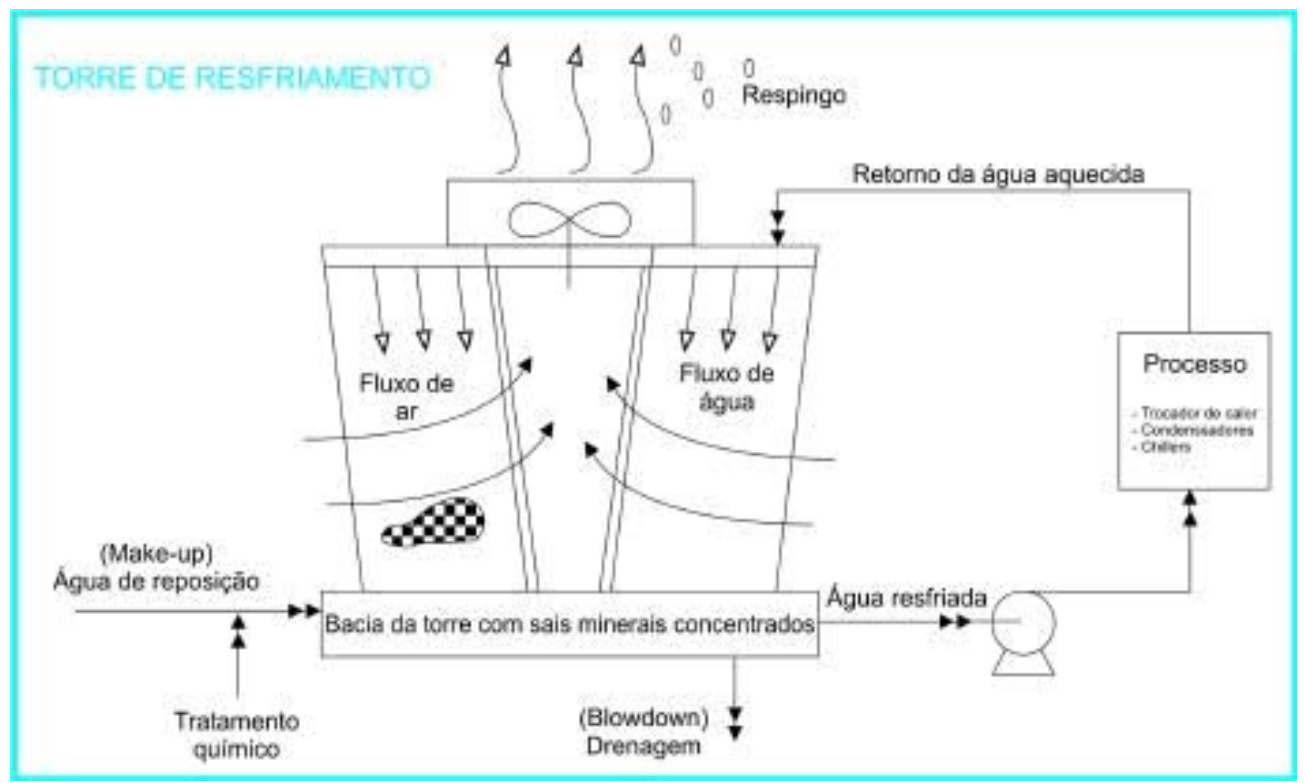

Figura 1 - Esquema de uma torre de Resfriamento

\subsection{Tratamento da água}

Quase toda torre de resfriamento bem cuidada usa um programa de tratamento de água. O objetivo deste tratamento é manter limpa a superfície dos equipamentos do processo, bem como minimizar o consumo de água e manter os parâmetros monitorados nos limites de descarte. Os parâmetros químicos críticos da água que requerem revisão e controle incluem $\mathrm{pH}$, alcalinidade, condutividade, dureza, crescimento microbiológico, concentração de biocidas e inibidores de corrosão. Dependendo da qualidade da água de make-up, os programas de tratamento devem incluir inibidores de corrosão e incrustação, juntamente com bactericidas. Estes produtos químicos normalmente são adicionados ao sistema através de dosadores automáticos. Os dosadores automáticos de produtos químicos, tendem a diminuir a quantidade de produtos químicos requerida. 


\section{TORRES DE RESFRIAMENTO DA CSN - CBR'S}

Grande parte das torres de resfriamento da CSN faz parte do setor de Utilidades e são denominadas de CBR's (casas de bomba de recirculação). Hoje no setor de Utilidades existem 8 grandes CBR's, cada uma atendendo a um determinado processo de produção. São elas:

- CBR\#4 - Refrigera o cadinho, ventaneiras, canhão de lama, Staves do Alto Forno 3;

- CBR\#26- Refrigera o cadinho, ventaneiras, canhão de lama, Staves do Alto Forno 2;

- CBR\#18- Refrigera a sala dos trocadores e equipamentos periféricos dos fornos de placa do Laminador de Tiras a Quente (LTQ\#2)

- CBR\#20- Refrigera os fornos de placa do LTQ2;

- CBR\#25 - Refrigera a sala dos trocadores do Laminador de Tiras a Quente (LTQ\#2)

- CBR\#14 - Refrigera os trocadores das linhas de tiras a frios 1, 2 e 3, Zincagens, Decapagem, Linha de Revestidos e Oficinas da laminação.

- CBR \#15- Refrigera as linhas de estanhamento, linhas de revestidos e acabamento.

- Torre da Central Termoelétrica - Refrigera os turbo geradores e auxiliares da Central Termoelétrica 2 (CTE\#2).

As figuras 2 e 3 a seguir, ilustram algumas de nossas CBR's.

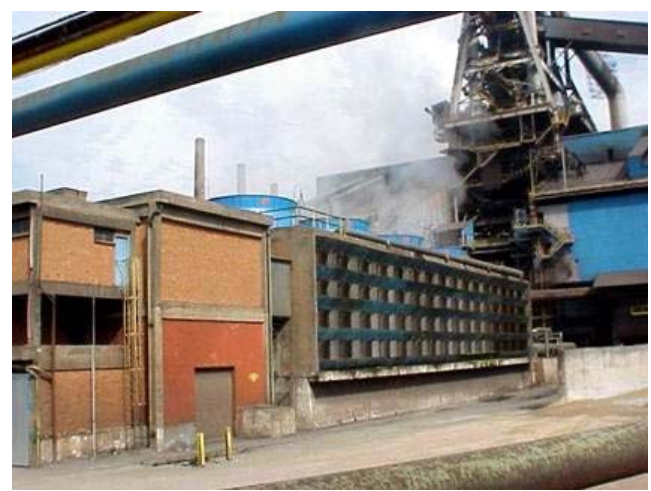

Figura 2 - Vista Lateral da CBR\# 4

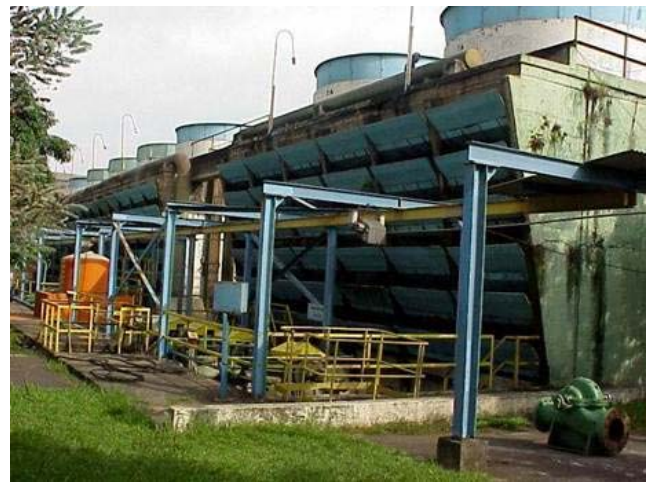

Figura 3- Vista Lateral da CBR 15 


\section{TRATAMENTO QUÍMICO NAS CBR'S}

O programa de tratamento para os sistemas de resfriamento é direcionado para controle de corrosão, incrustação e deposição dos compostos presentes na água, bem como controle da microbiologia destes sistemas. Estes programas visam:

- aumentar a vida útil das superfícies metálicas dos equipamentos, elevando a eficiência de troca térmica,

- reduzir custos de manutenção, pela diminuição de intervenções no sistema,

- reduzir o consumo de água de make up, minimizando o impacto ambiental.

Além dos produtos químicos que são aplicados na água de resfriamento, existem os equipamentos de aplicação e controle destas dosagens. Estes equipamentos têm o objetivo de evitar grandes variações de residuais de produtos, minimizar erros de dosagens e reduzir os riscos pela diminuição do contato dos operadores com os produtos químicos.

Para toda esta aplicação, controle de dosagens e residuais de produtos químicos, a CSN possui um contrato com uma empresa de tratamento químico que além de fornecer os produtos a serem dosados é a responsável pelas dosagens, monitoramento dos parâmetros de controle do tratamento através de análises em laboratório próprio instalado dentro do site da UPV e através de equipamentos instalados nas áreas, que realizam estas medições on line. A figura 4 ilustra um tipo de aplicação do produto químico em uma CBR.

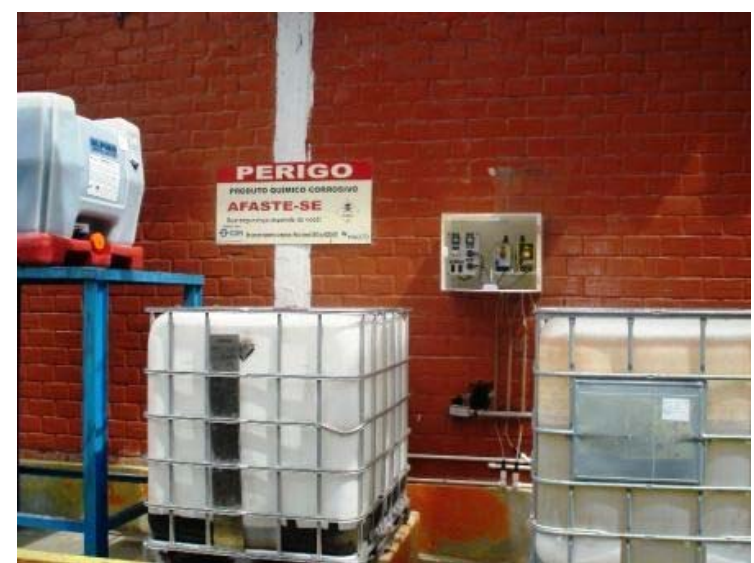

Figura 4- Dosagem de produtos em containers com bombas dosadoras

\section{OBJETIVO DO TRABALHO}

Este trabalho visa descrever os ganhos alcançados no último contrato feito com a empresa de tratamento químico das torres de resfriamento que compõe as CBR's do setor de Utilidades.

O contrato S10969676 foi assinado em 01/02/2014 com vigência de 01/06/2014 a 30/05/2016, porém o tratamento foi efetivamente iniciado nas áreas da UPV em Agosto de 2014.

As torres de resfriamento envolvidas neste contrato eram tratadas há mais de 10 anos, por outra fornecedora e todos os resultados estavam sob controle dentro das metas estipuladas pelo processo. 
Como a assinatura do novo contrato em 2014 e com a mudança do fornecedor, houve um receio geral da equipe de utilidades da CSN de como se comportaria os sistemas que até então estavam dentro nas metas de trabalho e bem monitorados.

Para a transição entre o antigo tratamento e o novo, houve um planejamento criterioso, para não haver interrupção das dosagens dos produtos, nem do monitoramento dos parâmetros de controle da qualidade de água, além de evitar riscos de interferência no processo de produção.

Este planejamento envolveu 5 etapas de trabalho, que foram:

- Primeira Etapa: Cadastramento e Compra dos novos Produtos a serem usados substituição de 9 produtos utilizados anteriormente por 6 novos produtos

- Segunda Etapa - Integração da nova equipe de trabalho, treinamentos, análise de risco.

- Terceira Etapa - Montagem em paralelo dos novos sistemas, com os antigos ainda operando e montagem do novo laboratório da contratada para atendimento ao novo contrato

- Quarta Etapa - Transição dos tratamentos do fornecedor antigo para o novo fornecedor, iniciando as dosagens e o monitoramento das áreas pelo novo fornecedor

- Quinta Etapa - Estabilização dos tratamentos no novo contrato e instalação dos monitoramentos automáticos dos sistemas de tratamento

\section{O NOVO CONTRATO}

O contrato iniciou efetivamente nas áreas em Agosto de 2014, seguindo todas as etapas planejadas, conforme citadas no item 4 deste trabalho.

Apesar de algumas dificuldades de atendimento iniciais, houve a estabilização dos sistemas após 4 meses de fornecimento e pode-se perceber grandes ganhos alcançados, principalmente nos custos do tratamento.

\section{RESULTADOS OBTIDOS}

\section{1) Manuseio de produtos químicos, armazenagem, transporte}

No contrato anterior aplicávamos cerca de 9 diferentes produtos, manuseando cerca de 23 toneladas de produtos em containers de $1000 \mathrm{~kg}$ por mês e 88 toneladas de produtos a granel por mês.

No contrato atual aplicamos 6 diferentes produtos, manuseando cerca de 17 ton de produtos em containers de $1000 \mathrm{~kg}$ por mês e 60 toneladas de produtos a granel por mês.

Em relação as quantidades dosadas anteriormente e as atuais, percebe-se que houve uma redução significativa de manuseio de produtos envolvidos nestes tratamentos. Esta redução de quantidades no contrato atual, trouxe uma economia no custo de armazenamento, que considera o custo do $\mathrm{m}^{2}$ armazenado, mão de obra agregada, IPTU, seguros e transporte envolvido no manuseio destes produtos.

Esta redução de quantidades de produtos manuseados, trouxe ganhos na produtividade na parte de manuseio e transporte de químicos, visto que houve uma redução de cerca de $26 \%$ de manuseio de containers de produtos químicos.

A economia alcançada neste novo contrato neste item foi de cerca de $\mathrm{R} \$ 14.100 /$ ano, conforme cálculo efetuado em conjunto com a equipe de armazenamento e logística da CSN. 


\section{2) Custo do Tratamento - Benefício Financeiro}

A figura 5 abaixo ilustra os débitos realizados nas áreas das torres de resfriamento em relação ao tratamento químico nos dois últimos anos (2013, 2014,2015 e primeiro trimestre de 2016) no setor de Utilidades da CSN (GGCE).

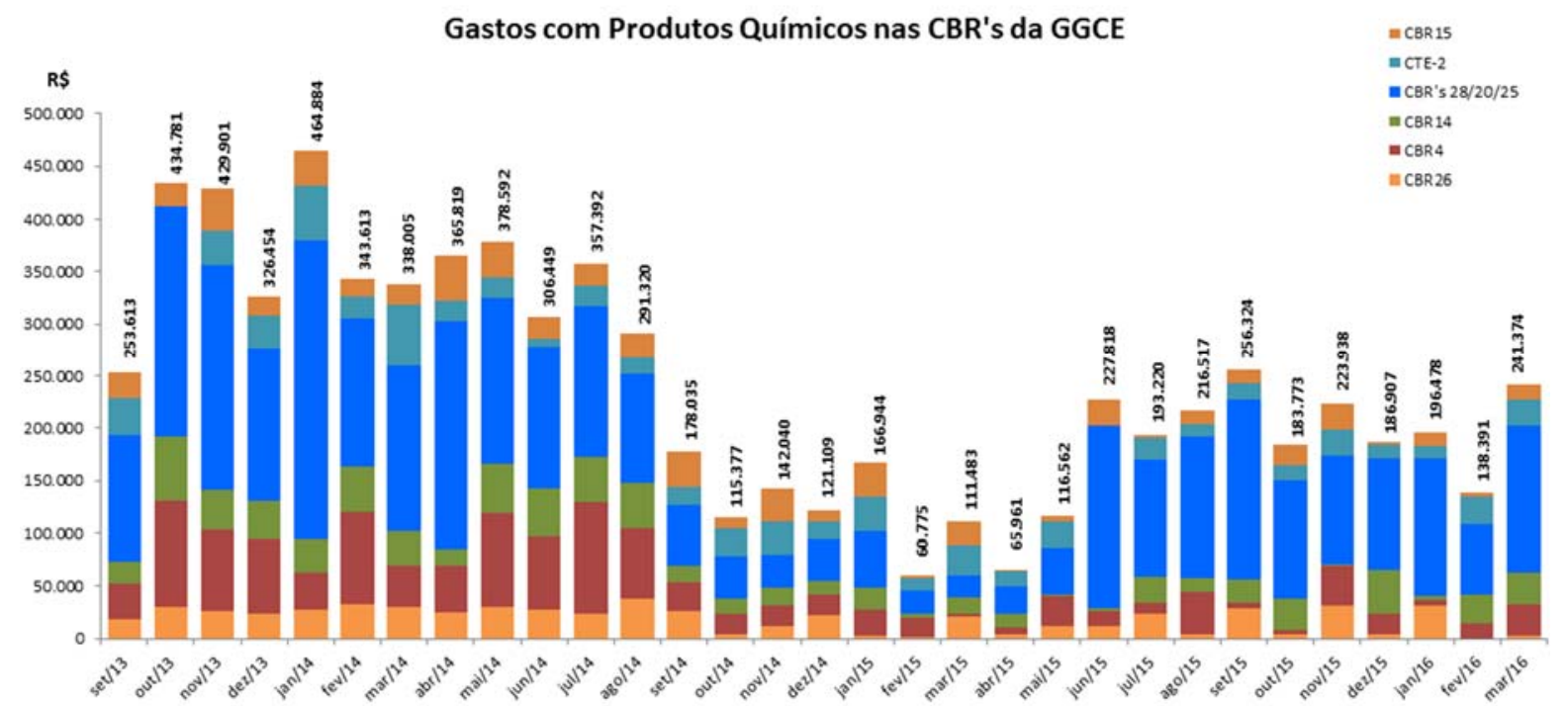

Figura 5 - Valores debitados em relação aos produtos químicos tratados nas CBR's - Fonte: SAP/R3

Considerando que de Setembro de 2013 a Agosto de 2014, na vigência do contrato anterior, foram gastos cerca de $R \$ 4,2$ milhões para tratamento químicos nas CBR's e de Setembro de 2014 até Agosto de 2015 foram gastos cerca de $R \$ 1,7$ milhões para realização do mesmo tratamento. Portanto, a economia alcançada com o novo contrato foi de cerca de $\mathrm{R} \$ 2,5$ milhões/ano.

\section{3) Parâmetros de Controle - Qualidade da água - Sustentabilidade}

Além da expressiva economia nos tratamentos químicos das CBR's, com transporte, armazenagem e produtos químicos, como citado nos itens acima, os parâmetros de qualidade de água se mantiveram dentro das metas estipuladas. As taxas de corrosão, por exemplo, que é um excelente parâmetro de controle da qualidade do tratamento, mantiveram-se nas faixas recomendadas alcançadas no contrato anterior.

A seguir, destacamos nas Figuras 6 e 7 os resultados alcançados em algumas das CBR's envolvidas: 


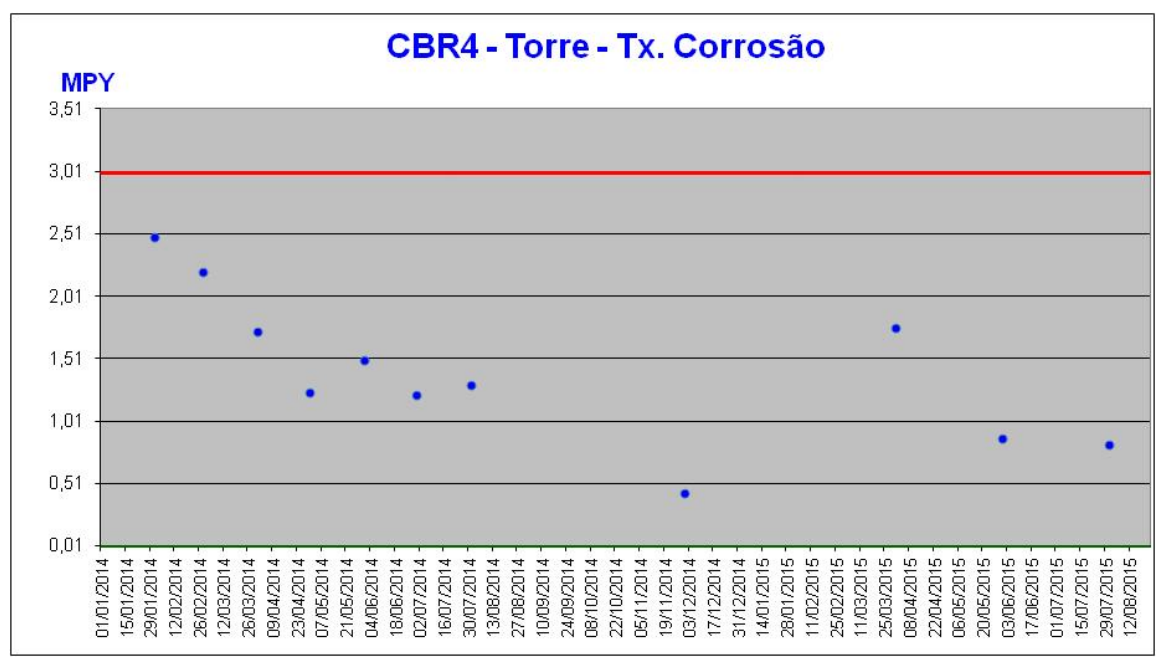

Figura 6. Taxas de Corrosão nas CBR's 4 e 25 desde 2014

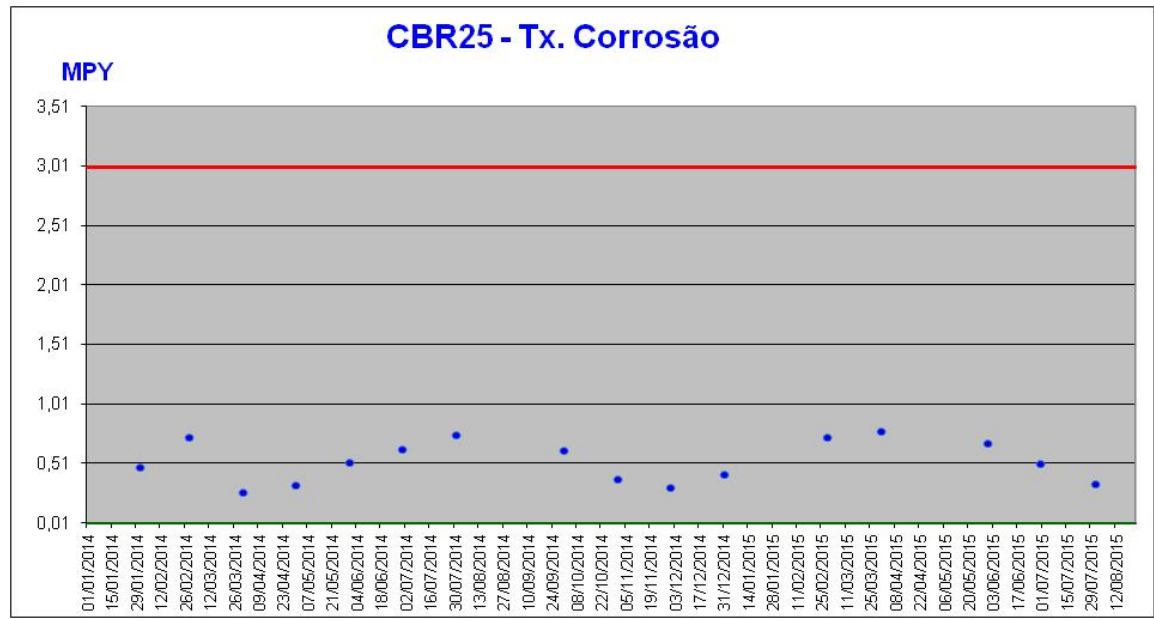

Figura 7. Taxas de Corrosão nas CBR's 4 e 25 desde 2014

\section{4) Outros avanços Obtidos no novo contrato}

Com o novo contrato, foram alcançados alguns avanços, tais como:

6.4.1) Acesso on line dos resultados medidos nos sistemas de resfriamento via internet, conforme Figura 8 a seguir.

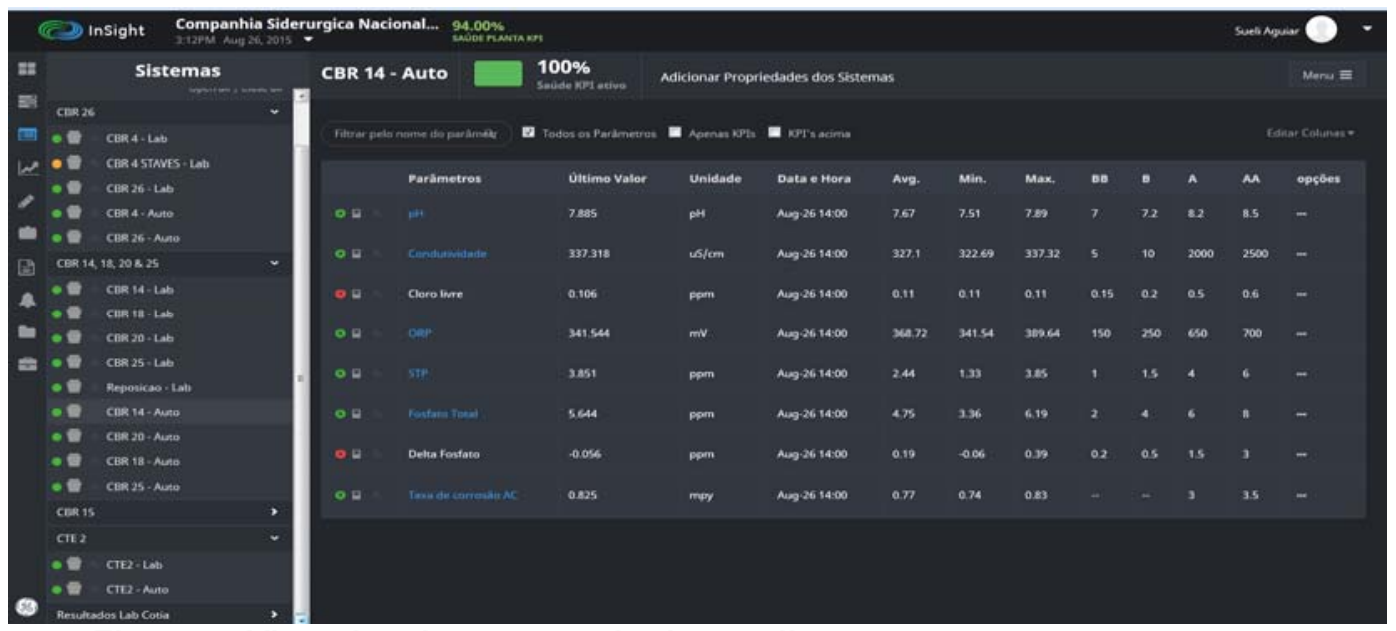

Figura 8. Vista da tela com resultados on line 
6.4.2) Análise de Legionella bimensalmente que foi inserida no novo contrato- $A$ infecção por Legionella transmite-se por inalação de gotículas de vapor d'água contaminada, aerossóis, que veiculam esta bactéria para os pulmões. Portanto, todos os equipamentos de refrigeração que geram aerossóis precisam ter este tipo de controle. Em países europeus este controle é obrigatório. No Brasil, algumas empresas já realizam. Neste contrato, foi introduzido o monitoramento bimensal de nossas torres.

6.4.3) Medição das Taxas de Corrosão do Sistema Staves do Alto Forno 3 - Este sistema de fundamental importância na refrigeração das paredes do forno não tinha monitoramento de corrosão e com o novo contrato, foi introduzido esta importante medição.

6.4.4) Restabelecimento do Sistema de Abrandamento da CBR 4- Este sistema não estava funcionando corretamente e com o novo contrato, foram identificados vários pontos de melhoria neste sistema, melhorando significativamente a qualidade do tratamento de água abrandada.

6.4.5) Redução das Taxas de Corrosão nos fornos de Placa do Laminador de Tiras a Quente 2, através do trabalho em conjunto com a equipe da contratada e da produção para redução dos pontos quentes nos fornos. Foi introduzido o monitoramento da água em cada forno, além do monitoramento realizado na CBR e um controle rigoroso do pH e da corrosão.

\section{CONCLUSÃO}

Todo processo de mudança gera um ambiente de expectativas e receios. Porém, este trabalho provou que a mudança efetuada para um novo fornecedor nos tratamentos químicos das CBR's foi eficaz economicamente, trazendo uma economia de mais de $\mathrm{R} \$ 2,5$ milhões no último ano, além de manter os parâmetros de qualidade de água garantidos aos processos de produção.

É claro que os resultados alcançados só foram obtidos através do controle rigoroso dos consumos nas áreas, o acompanhamento diário das dosagens e dos resultados analíticos dos sistemas, além de uma boa integração da equipe da contratada com a de utilidades.

Este trabalho é contínuo e precisa ser monitorado diariamente e o desafio atual é buscar maior integração com os processos de produção, buscando os melhores resultados alcançados mundialmente nestes sistemas de resfriamento, sem 0 incremento nos custos de tratamento.

\section{REFERÊNCIAS}

1 Manuais de Operação das CBR's

2 Mc Graw Hill - The Nalco Water Handbook - Second Editon 